\title{
Investigating the strength of linkages of plant health institutional and legislative framework in South Africa
}

Rambauli, M. ${ }^{1}$, Antwi, A.M. ${ }^{2}$, Mudau, F.N. ${ }^{3}$

Corresponding author: M Rambauli. E-mail: mrrambauli@gmail.com

\begin{abstract}
This paper presents existing linkages within the spheres of government on plant health institutional and legislative framework and further identifies the existing limitations and risks on current existing framework on plant health system. A survey was conducted in South Africa with the relevant scientists from the National Department of Agriculture, Land Reform and Rural Development (DALRRD) formerly known as Department of Agriculture, Forestry and Fisheries (DAFF) and Department of Environment, Forestry and Fisheries (DEFF) formerly known as Department of Environmental Affair (DEA) as well as extensionist and agricultural advisors from 7 Provincial Departments of Agriculture (PDAs).. The sample size of the study was 60 government officials from both national and provincial department of agriculture. A semi-structured questionnaire was used to collect the data. The data was analysed statistically using the one-way frequency and Spearman's Rank correlation coefficients. This paper revealed that there were no formal linkages between the relevant national government and PDAs in terms of legislative and policy prescripts on plant health issues. The study further revealed that there is a need to establish the plant health unit to coordinate plant health matters from the National Plant Protection Organisation of South Africa. On the aspect of biosecurity legislative framework affecting food production and security as well as trade, the study found that there is no cross referencing amongst relevant legislation; therefore, there is a need for harmonisation of relevant legislation.
\end{abstract}

Keywords: Extensionist, food production and security, legislation, harmonisation, plant health institutional framework.

\section{INTRODUCTION}

Plant health is a discipline within which science based knowledge is applied within the regulatory framework system for the protection of plants and plant natural resources from

\footnotetext{
${ }^{1}$ Scientist Manager and the Executive Officer of the Agricultural Pests Act, 1983 (Act No.36 of 1983), Division Policies, Norms and Standards, Directorate: Plant Health, Department of Agriculture, Land Reform and Rural Development, Private Bag X14, Gezina, Pretoria, 0031, E-mail: MaandaR@Dalrrd.gov.za

2 Professor: Postgraduate Research Coordinator for Master and PhD in Agriculture, College of Agriculture \& Environmental Sciences (CAES), Agriculture \& Animal Health Department, University of South Africa, Florida Campus, Calabash Building, Room 332B; e-mail: antwima@unisa.ac.za; https://orcid.org/000.0003-3896-4502

${ }^{3}$ Professor; Dean \& Head of School: School of Agricultural, Earth and Environmental Sciences, University of KwaZulu-Natal, P. Bag X01, Scottsville 3209, Pietermaritzburg, South Africa, MudauF@ukzn.ac.za; https://orcid.org/0000-0003-3623-6421
} 
harmful plant pests (Ebbels, 2003). Plant health regulations or phytosanitary regulations are significant within the framework of the plant health system (RSA, 2014). Plant health regulations refer to the official rule to prevent the introduction, establishment and/or spread of quarantine pests or to limit the economic impact of regulated non-quarantine pests (FAO, 2007). According to Vapnek and Manzella (2006), plant health legislation is significant in protecting plant natural resources from the introduction, establishment and spread of harmful pest.

Plant health regulations are considered to be the critical mechanisms in preventing and combating plant pests of economic importance, especially the exotic and/or quarantine pests (Schrader \& Unger, 2003). Zhou and Kuhlmann (2015) defined regulations as sets of measures which should be executed in order to achieve the object of specific legislation. The International Plant Protection Convention (IPPC), which is an international treaty on plant health matters, requires that contracting parties to this Convention shall develop and issue plant health regulations (FAO, 2011). Within the context of the IPPC, most of the government institutional arrangements through the establishment of the National Plant Protection Organisations (NPPO), for an example South Africa (SA) have an obligation to prevent the introduction, establishment and spread of plant pests and diseases which may negatively impact on international trade (Msiska et al. 2013; FAO, 2011).

According to CABI (2017), proper advisory mechanism, policy and legislative instruments are critical to assist farmers in controlling and management of pest. Furthermore, plant pests and diseases if not properly managed may compromise the availability of food which may lead to food insecurity in a country. It is estimated that plant pests and diseases of economic importance could cause plant production losses of about 30-40\% (Oerke, 2006).

Globally, plant health matters (including relevant courses or subjects) do not receive more attention in many universities. Similarly, there are limited scientific publications in relation to plant health or phytosanitary field (Ebbels, 2003). There is also limited scientific publication information within the African region on plant health issues (Flood, 2010). This study fundamentally caters for the analysis of the linkages and strength relating to selected plant legislative and institutional framework within the spheres of government of the Republic of South Africa.

\subsection{OBJECTIVES OF THE PAPER}

The study was conducted to assist the relevant government departments; policy makers and agricultural advisors/extension services support in order to make informed relevant recommendations on the current plant health system and to ensure that appropriate interventions are executed. The fundamental purpose is to provide for the effective plant health system within the spheres of government and determine linkages of plant health legislation with other selected relevant legislation. The specific objectives of this research paper are to: 
- Investigate the effectiveness and strength of institutional arrangement.

- Establish an effective and legitimate linkages and/or working relations within the spheres of government.

- Identify critical areas and gaps to be addressed in the current institutional framework of national and provincial departments of agriculture in South Africa.

- Identify the limitations and risks in the existing or current legislation on phytosanitary matters.

- Harmonisation of relevant pieces of legislation dealing with concurrent issues.

\section{LITERATURE}

South Africa is signatory of the World Trade Organization Agreement on the Application of Sanitary and Phytosanitary Measures (WTO-SPS Agreement) and the IPPC (IPPC, 1997; WTO, 2010; Lukauskas, Stern \& Zanini, 2013 \& RSA, 2014). According to Article I of the New Revised Text of the IPPC (1997), "Members are required to adopt the legislative, technical and administrative measures of this Convention". Furthermore, Article VI of the IPPC requires that a country (such as South Africa) to provides for the general provisions relating to the organisational or institutional framework for the establishment of the "national plant protection organisation" (NPPO).

It requires that "member country shall make provision, to the best of its ability, for an official national plant protection organisation to discharge its main phytosanitary responsibilities" (FAO, 2011). Within the context of "Article IV of the IPPC", South Africa had established "the National Plant Protection Organisation of South Africa" (NPPOZA) to discharge its responsibilities in accordance with the provisions of the IPPC (RSA, 2014). South Africa is also a member of the Regional Plant Protection Organisation (RPPO) which is the Inter-African Phytosanitary Council (IAPSC). The RPPOs function as coordinating bodies in plant protection matters as well as in gathering and disseminating information with the African region (IPPC, 1997; Chinappen, 2011). According to SADC (2001), South Africa became a signatory to the SADC in 1994.

In South Africa, the competency in dealing with phytosanitary matters is within the national department which is the Department of Agriculture, Land Reform and Rural Development (DALRRD), formally known as Department of Agriculture, Forestry and Fisheries (DAFF): National Plant Protection Organisation of South Africa (NPPOZA), directorates Plant Health (DPH) and Inspection Services (DIS) as well as Food Import and Export Standards (DFIES). The provision of which is an obligation in terms of Article IV of the IPPC which provides for the South Africa's signatory membership of the IPPC (RSA, 2014). However, other element of biosecurity which is related to phytosanitary matters is embodied with the Department of Environment, Forestry and Fisheries (DEFF), formerly known as Department of Environmental Affairs (DEA) (DEA, 2015). 
According to the RSA (2014) and Chinappen (2011) each government should play an important role in protecting plant health status of its territory in order to ensure safe and fair trade. Ogden (2012) suggested that effective linkages amongst organs of state and various role-players is a key factor for the effective management of plant pests. Furthermore, Shaun (2016) indicated that the linkages within the framework of the plant health system is critical for agricultural sustainability which, include the linkages with various role-players, agricultural extension services, regulatory and policy framework authority as well as research components.

In South Africa, the legislative mandate of the DALRRD on the control and management of plant quarantine pests and diseases is the Agricultural Pests Act (APA), 1983 (Act No.36 of 1983) and its associated regulations (RSA, 1983; DAFF, 2015a). This mandate is within the national competency and performed by the NPPOZA which is the requirement in terms of South Africa's membership to the IPPC. The purpose of the APA with regard to phytosanitary matters is to provide for measures by which quarantine pests of plants, plant products and associated regulated articles may be prevented from entering, establishing and spreading in South Africa. The powers and functions to execute the provisions of the APA are vested on the relevant national executive officers in terms of the APA (RSA, 1983).

Areas of concurrent, in plant health or phytosanitary matters remain with the DALRRD which is the national department. These include policy formulation, implementation and in terms of institutional arrangements (DAFF, 2015a). According to AU (2013), most of the plant health legislative framework is outdated and there is a need for a comprehensive review. During the drafting of this paper, South Africa was still in the process of legislative reform of plant health matters (RSA, 2014 \& 2017). In most African countries, the NPPOs functions are not mandated to provincial government although some functions are outsourced from private sector (AU, 2013).

According to section 27 of the Constitution of the Republic of South Africa, (1996) "everyone has the right to have access to sufficient food... and the state must take reasonable legislative and other measures, within its available resources, to achieve the progressive realisation of each of these rights'. The legislative mandate of the agricultural sector is emanated from section 27(1) (b) of the Constitution (RSA, 1996; DOA, 2002; DAFF, 2011).

In South Africa, there is APA with its subordinate legislation which are published in terms of enabling sections with the purpose to provide for prevention of introduction and spread of pests of plants and plant products such as Regulations R.111 of 27 January 1984 (R.111); Government Notice of 26 May 1989 (R.1013) and R.110 of 27 January 1984 (R.110) (DAFF 2015b). According to the RSA (2014), the following relevant legislation are selected based on the cross-cutting issues relating to the administration and implementation of phytosanitary measures on import and national control:

- Plant Improvement Act, 1976 (Act No. 53 of 1976) (PIA)

- Genetically Modified Organisms Act, 1997 (Act No. 15 of 1997) (GMOA) 
- Plant Breeders' Rights Act, 1976 (Act No. 15 of 1976) (PBRA)

- National Environmental Management Biodiversity Act, 2004 (Act No.10 of 2004) (NEMBA)

- Fertilizers, Farm Feed, Agricultural Remedies and Stock Remedies Act, 1947 (Act No. 36 of 1947)

- Intergovernmental Relations Framework Act, 2005 (Act No.13 of 2005)

In the United States of America (USA), although there is a national law on plant health such as the Plant Quarantine Act, 2000, there are Federal legislation executed by the states at provincial level in order to control and manage plant pests and diseases (USDA, 2017). In Australia, the Plant Biosecurity system is effective and it involves provincial or states authority through the "intergovernmental agreement on biosecurity" to ensure affective coordination between the national government and local authority. In the European Union, the plant health regulatory framework was harmonised since 1993 in accordance with the international prescripts (Schrader \& Unger, 2003). In South Africa, there is the Intergovernmental Relations Act which can also be implemented to ensure the good working relation with provinces (RSA, 2005). Lack of institutional capacity and poor co-ordination within spheres of government, in the Republic of Kenya affected the horticultural production in the past (RK, 2010).

\section{RESEARCH METHODOLOGY}

The study was conducted in South Africa targeting employees from the following departments: DALRRD, DEFF and PDAs. Research data was obtained through a semi-structured questionnaire which was both qualitative and quantitative research design. The questionnaire was designed to gather information on plant health system. These include biographical information and knowledge on plant health matters, linkages on the institutional and legislative framework. The questionnaires for the survey were circulated and distributed directly to the main role-players using various mechanisms such as e-mail, hand delivered as well as direct face to face interview.

Stratified Random Sampling was used and data was collected from the scientists, inspectors, biodiversity officers, agricultural advisors or extension officers of DALRRD, DEFF and PDAs respectively. The data were collected from the total of 60 respondents at the DALRRD, DEFF and PDAs. Data was collected from 30 respondents from National departments (DEFF and DALRRD) and 30 respondents of the 7 PDAs. The collected data was deemed to be representative from the total sample population on plant health disciplines and related fields. All fully completed questionnaires were coded and captured using the Statistical Package for the Social Science (SPSS. Version 20). Incomplete questionnaires were discarded. The data was analysed statistically using the one-way frequency and Spearman's Rank correlation coefficients with the SPSS computer software. 


\section{RESULTS AND DISCUSSION}

\subsection{Respondent demographics}

The results show that most of the participants were scientists (33.3\%) at the national level and $97.6 \%$ of the respondents at the PDAs were agricultural advisors. Plant Health is a science based disciplines and requires academically qualified personnel with scientific background (including plant pathology and entomology) to optimally function towards achieving the protection of plants from harmful organisms (Ebbels, 2003). Regarding work experience, the results indicated that half of the respondents $(50 \%)$ with an extensive experience in agriculture are located at the provincial level as compere to respondents $(36.7 \%)$ at the national departments.

\subsection{Existing institutional linkages on plant health system of South Africa}

The findings regarding linkages are presented in Figure 1. The results indicate that most of the participants at a national level $(86.7 \%)$ believed that there are linkages of the NPPOZA on plant health system to other government authorities whereas only $40 \%$ of the respondents at the PDAs believed so. However, $50 \%$ of the respondents at the provincial level agreed that the linkages do not exist between national authority and PDAs on plant health issues. To establish if the linkages were formal, the respondents were asked if these linkages were based on institutional and policy base.

The study revealed that there were different levels of understanding from both the national and provincial authorities. Many respondents $(80 \%)$ at the national level were of the opinion that those were formal linkages from the NPPOZA to other authorities exist, for an example the linkages between DALRRD and DEFF. The respondents at the provincial level $(76.7 \%)$ indicated that those formal linkages between the national and provincial level were not formal and do not exist.

The case study conducted by Hanyani-Mlambo (2002) defined formal linkages as those linkages that are institutionalised, policy and legislative based. Linkages between national and the provincial authority should be formalised through memorandum of understanding, policy and legislative prescripts. This is because there are different perceptions on the existence of formal linkages between the national and provincial authority. In relation to the linkages with the research institutes, the findings indicate that the majority of officials within the national (70\%) and provincial (56.6\%) authorities believe that the plant health system of South Africa formally linked well with the research organisations, such as the Agricultural Research Council (ARC). These linkages are found to be formalised through memorandum of understanding i.e. DALRRD and ARC. 
This is consistence with the study conducted by Hanyani-Mlambo (2002) who indicated that formal linkages should be based on policy prescripts. This was supported by Shaun (2016) who suggested that the linkages of the plant health system are critical for agricultural sustainability and these include the linkage with various stakeholders, agricultural extension services, regulatory and policy framework authority as well as research components. Overall, the foundation of plant health system of SA in terms of the plant health institutional framework is sound, however, it should be formalised, especially with the PDAs.

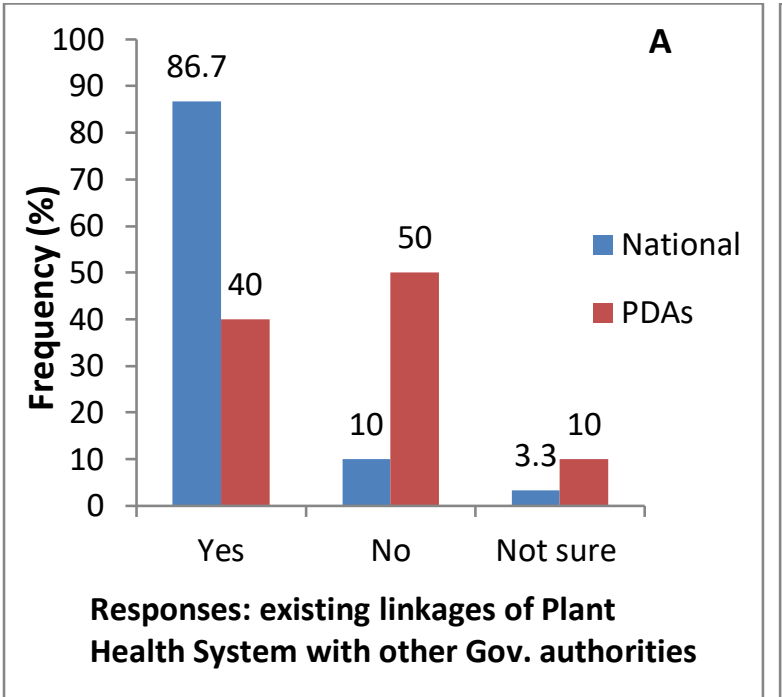

C

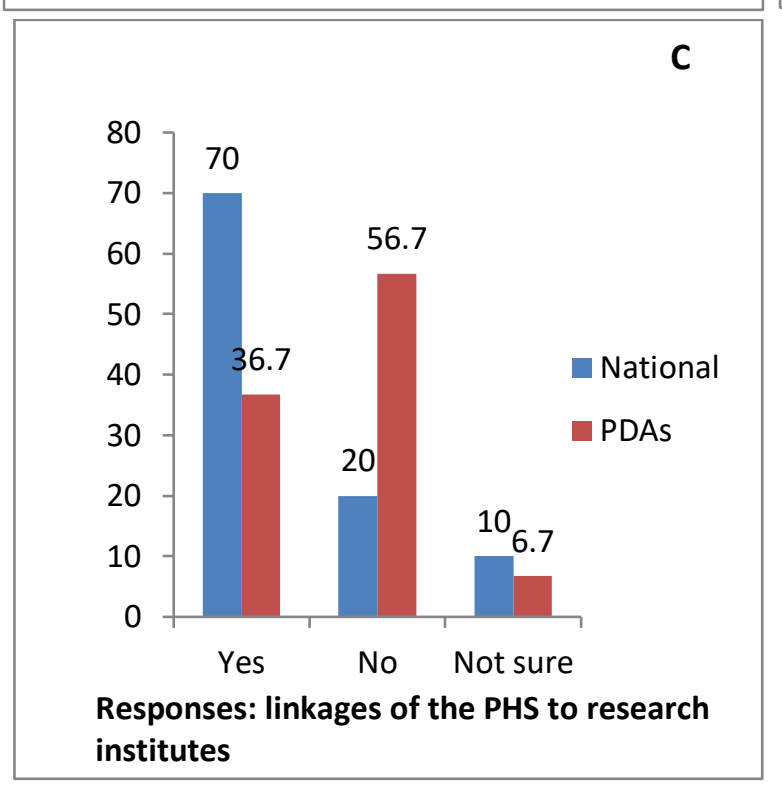

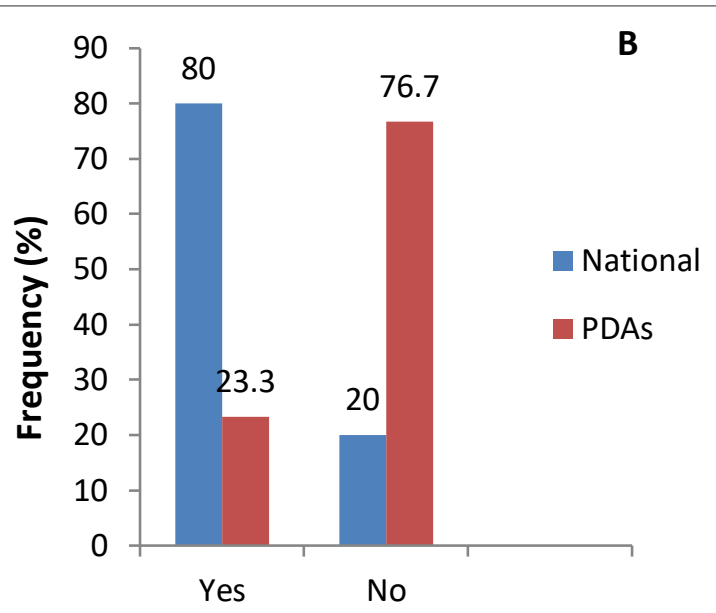

Responses: knowledge of existing formal linkages

Figure 1 Responses of the respondents regarding linkages of the NPPOZA on plant health system to other relevant authorities, any knowledge of existing formal linkages and linkages with research institution/s $(N=60)$

\subsection{Existence of the plant health unit within the relevant spheres of government}

The results of the existence of the plant health unit within the relevant spheres of government are presented in Figure 2 in a form of percentages. The respondents from the national and the 
provincial level were asked if the plant health unit exists in their respective components: the findings showed that the majority $(76.7 \%)$ of respondents at the relevant national authorities indicated that the relevant units or components on plant health matters do exist. However, $66.7 \%$ of the respondents at the PDAs indicated that such units or components do not exist at the provincial level. The respondents were asked if such unit should be established at the provincial level: the majority of the national and provincial respondents, $90 \%$ and $80 \%$ respectively, indicated that there is a need for the establishment of the plant health unit at provincial level or PDAs. This finding was supported by Danielsen and Matsiko, (2014) in a study conducted in Uganda who suggested that before the commencement of any reform on the mandate a deliberation should be fast-tracked to redefine the plant health mandate for better understanding within the national and provincial authorities. The control of plant pest and diseases of economic importance is administered by competent authority in many countries (IPPC, 2017).

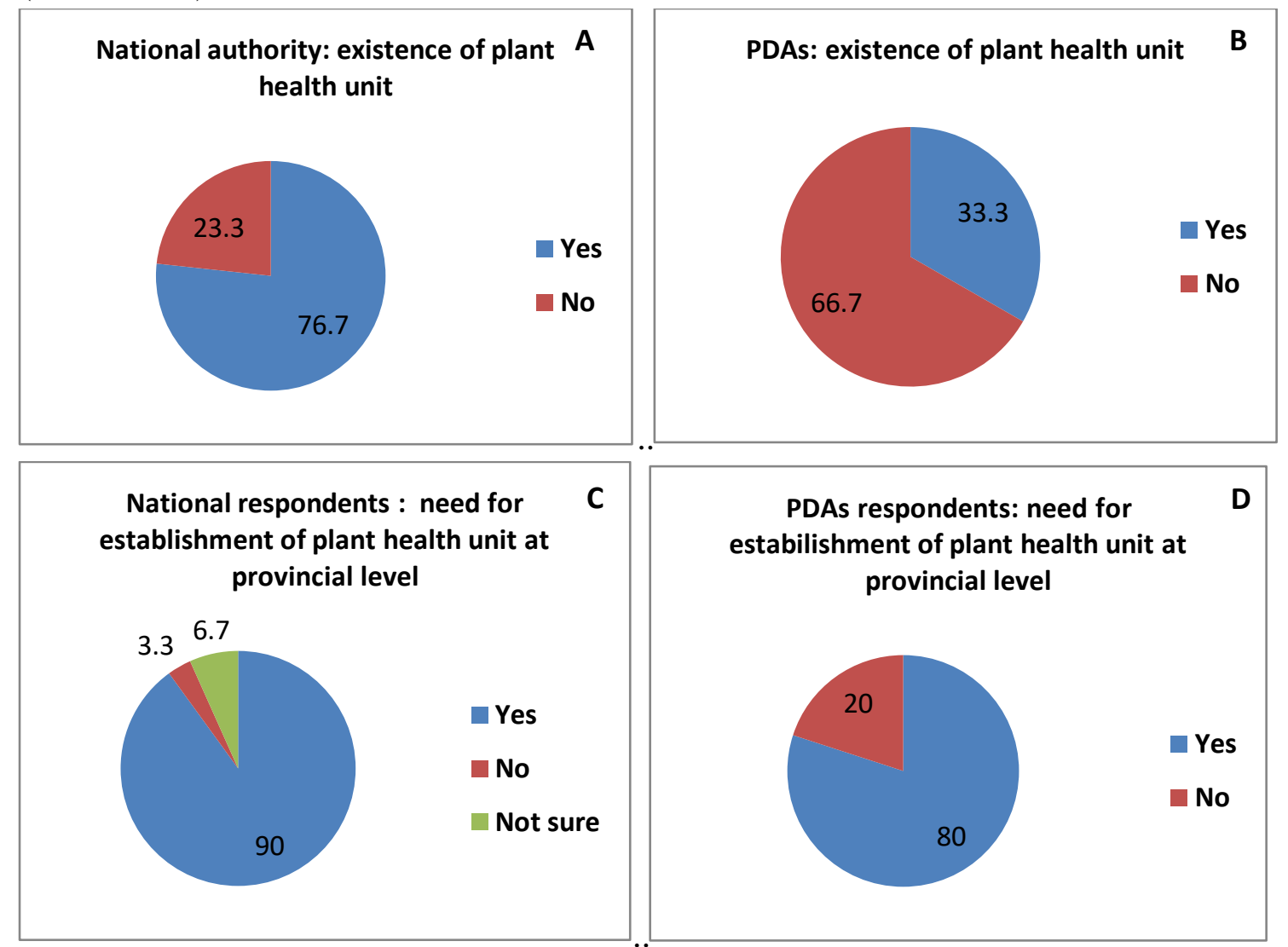

Figure 2 Responses of the respondents regarding existence of plant health at national authority vs provincial authority and responses from both national and provincial respondents in terms of the need for the establishment of the plant health unit at provincial level $(\mathrm{N}=60)$

\subsection{Cooperative models for pest control}

The findings in Figure 3 show the existence of cooperative models for pest control in South Africa. The respondents at the national $(50 \%)$ and provincial $(63.3 \%)$ authorities were not 
aware of the inclusive cooperative or collaborative models in South Africa in combating plant pests and diseases which may affect trade and production. Despite these findings the DAFF (2013) and RSA (2014) provides for collaborative approaches to control emerging plant pests on the plant health policy and emergency plant pest response plan. In the USA the cooperative models with all major roles players have been established to combat plant pests and diseases which involves the universities, research institutions, states/provincial and local authority, and industry as well as the community in general (USDA, 2015 \& USDA, 2017). In South Africa, there are various Steering Committees between government and stakeholders on plant health which the majority of the respondents are not aware of. The findings proved that broader drastic consultation and awareness which involved all relevant role-players should be embarked on to elaborate on the roles and responsibilities in relation to pest management and control. Most of the collaborative models listed by the national respondents were Joint Steering Committees on various pests such as: Fall armyworm Steering Committee, Bactrocera dorsalis Steering Committee and these involve industry, provinces, Agricultural Research Council (ARC). It is important that the control of plant pests and diseases should involve general public and community through awareness program is an effective tool for "coordination mechanism" (Chinappen, 2011).

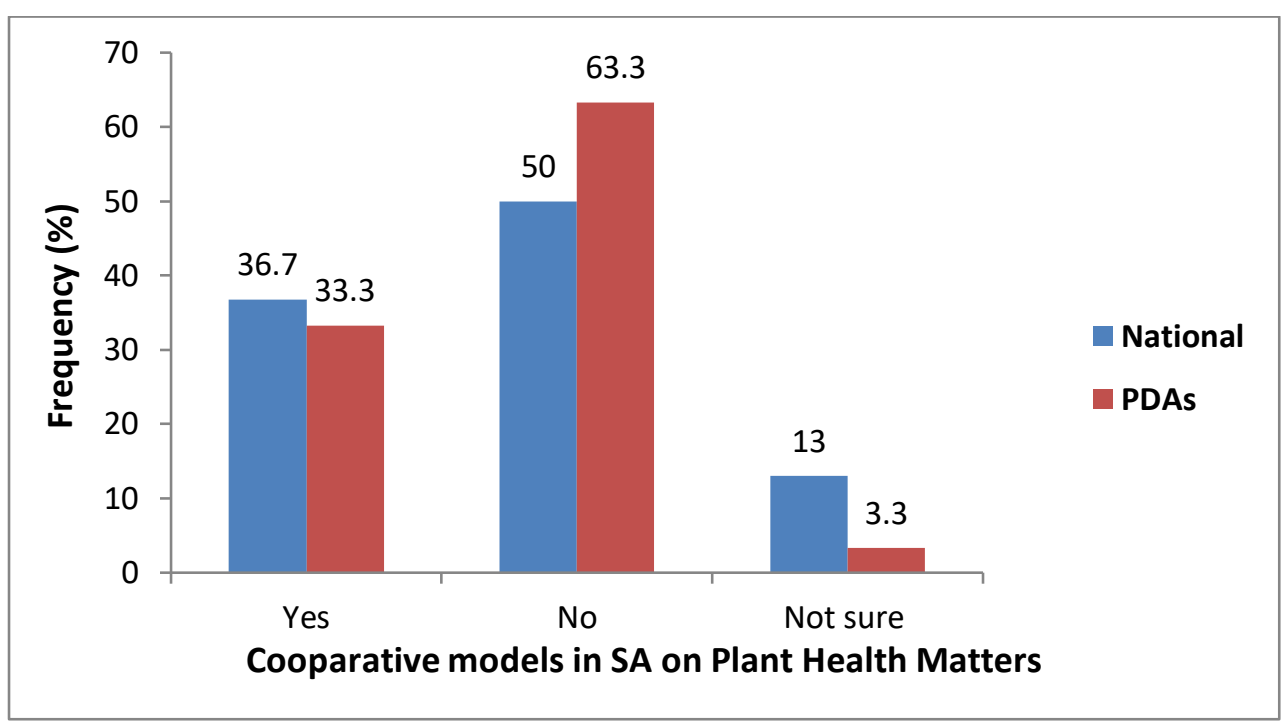

Figure 3 Responses of the respondents regarding existence of cooperatives models in SA for plant pest control $(\mathrm{N}=60)$

\subsection{Cross referencing and harmonisation between relevant pieces of legislation}

The results in relation to cross referencing of the selected pieces of legislation (see point no.1.6) are presented in Figure 4. The majority of respondents, at the national (70\%) and at the PDAs (73.3\%) believed that there is no clear cross referencing among the selected pieces of legislation. Alberts \& Moolman (2013) supported these results and pointed out that there are still fragmentation between the APA and NEMBA especially on the importation of the biological control agents and the release thereof. In addition, more respondents from both the 
national (56.7\%) and PDAs (60\%) concur that there is a need for harmonisation of the pieces of legislation such as Agricultural Pests Act, 1983 (Act No.36 of 1983) (APA), NEMBA, PIA and Act 36 of 1947 especially on the import provisions. The respondents believe that if cross referencing and harmonisation is applied, "this will promote access to information and enhance service delivery". Furthermore, officials from the PDAs also believe that "if all section dealing with import provisions can be interlinked within relevant legislation, there would be less contradictions and more clarity". Others further suggested that "it will improve efficiency and effectiveness".

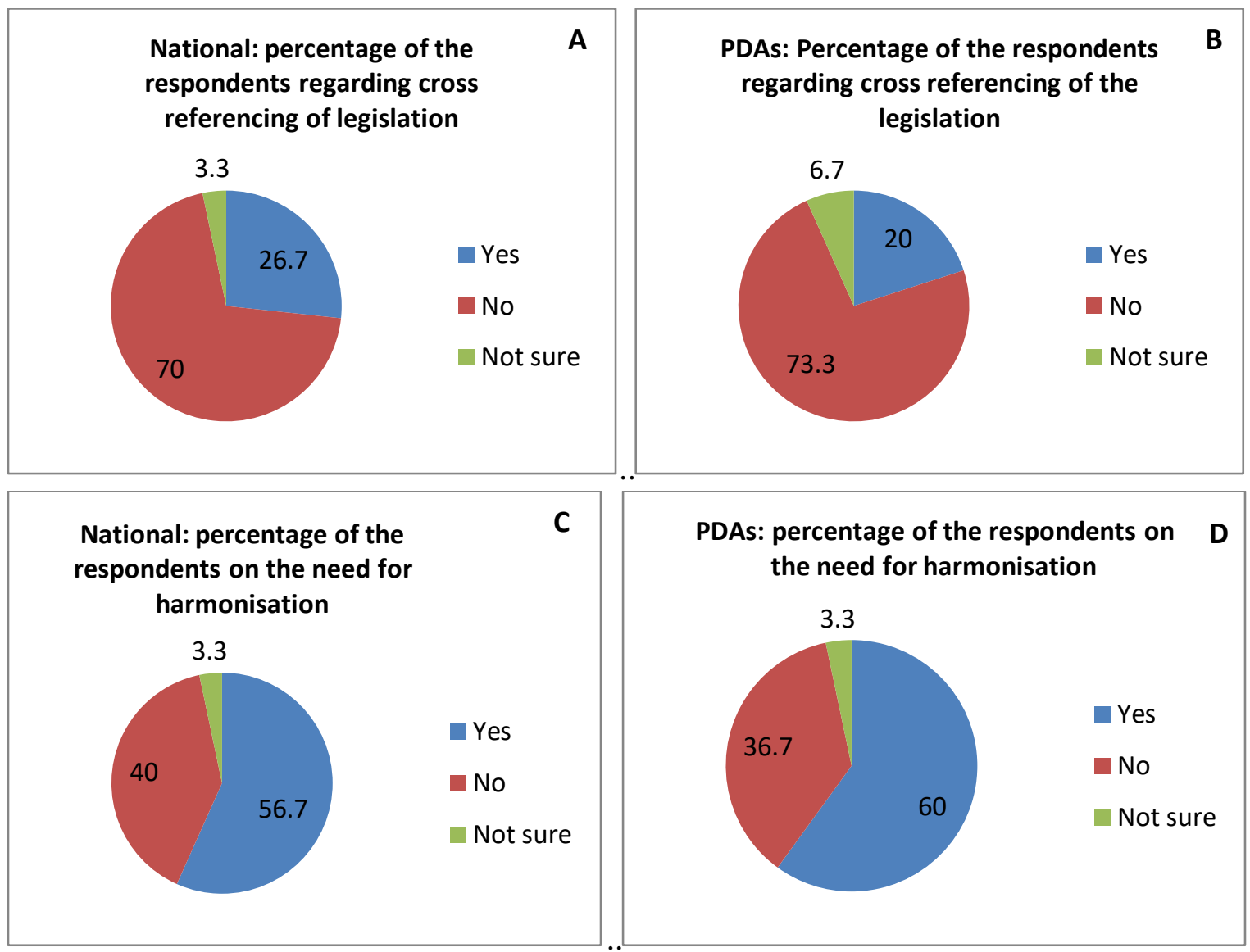

Figure 4 Percentages of the respondents from the national and provincial level on the existence of cross referencing and cross-references within the selected pieces of legislation $(\mathrm{N}=60)$

\subsection{Correlation coefficient analyses on the legislative and institutional framework}

A spearman's rank correlation coefficient was employed to determine the relationship between various variables in this study in relation to legislative and plant health institutional framework. The results of the correlation coefficient analysis are presented in Table 1.

\subsubsection{Inconsistency on the selected pieces of legislation and harmonisation}


There was correlation between the inconsistency on the selected pieces of legislation and harmonisation $((\mathrm{r})(60)=0.269, \mathrm{p}=0.038)$. It is expected that if there are inconsistency on the existing legislation, harmonisation on areas of concern should be employed, where necessary. In this study, more than $55 \%$ of the respondents from national and provincial departments of agriculture indicated that harmonisation must be considered on the selected pieces of legislation. For an example, relevant provisions of the APA, NEMBA and PIA on importation of plants, plant products and other regulated articles. The inconsistency is evidently revealed in the current draft Alien and Invasive Species Regulations R. 112 of 16 February 2018 which does not provide for linkages or cross-referencing to the APA regarding the biological control agents (DEA, 2018).

\subsubsection{Inconsistency amongst selected pieces of legislation and cross referencing}

The correlation between inconsistency issues amongst selected pieces of legislation and cross referencing amongst legislation was presented and it was found that there was a positive correlation which was significant $((\mathrm{r})(60) 0.0333, \mathrm{p}=0.009)$. In cases where there is inconsistency amongst the legislation, especially on import of plants, plant products and other regulated articles, cross referencing is expected to be established through legislative instruments.

\subsubsection{Overlapping issues in the selected pieces of legislation and need for harmonisation}

Likewise, the results in terms of the correlation between overlapping issues on the selected pieces of legislation and need for harmonisation on the areas of concern was found to be strong and positive $((\mathrm{r})(60)=393, \mathrm{p}=0.002)$. It implies that where there are overleaping issues amongst the legislation, this can be addressed through policy and legislative parameters. As indicated above, the findings indicated that there is a need for harmonisation on the provisions of legislation to improve efficiency.

Table 1: Spearman's correlation coefficients on the strength of the existing legislation related to the plant health system of South Africa $(n=60)$

\begin{tabular}{|l|l|l|}
\hline Variables & Harmonisation & Cross referencing \\
\hline Inconsistency & $0.269^{*}$ & $0.333^{* *}$ \\
\hline Overlapping & $0.393^{* *}$ & $0.143^{\mathrm{NS}}$ \\
\hline
\end{tabular}

Correlations are highly significantly $(* *)$, significant $(*)$ at $\mathrm{p}<0.05$ or non-significant $(\mathrm{NS})$

\subsection{Correlation coefficient analyses regarding formal linkages on plant health matters}

The results of the correlation coefficient analysis regarding formal linkages on plant health matters are presented in Table 2. 


\subsubsection{Effect of formal linkages in participation to relevant plant health}

The results of the association between the formal linkages from the NPPOZA to other units and the level of participation in relevant plant health forums was found to exist ((r) $(60)=0.333$, $\mathrm{p}=0.009$ ). Formal linkages within the structure of the plant health system can encourage participation in relevant fora. Hanyani-Mlambo (2002) suggested that most of the formal linkages amongst the institutions are based on the documented procedures, responsibilities and goals. In South Africa, formal linkages are based on policy and legislative framework, memorandum of understanding/agreement (MOU/A), Service Level Agreements (SLA). Furthermore, other relevant forums are established in terms of the Terms of Reference being developed with all role-players.

\subsubsection{Effect of formal linkages to knowledge of the Agricultural Pests Act, 1983}

As this study is focused on the plant health system of South Africa, the results of the connection between the formal linkages to knowledge of the Agricultural Pests Act, 1983 (Act No. 36 of 1983 ) in the national and provincial authorities was analysed and found to be a positive connection which was statistically significant $((\mathrm{r})(60)=0.434, \mathrm{p}=0.001)$. Formalised linkages from the NPPOZA structure with other relevant authority will influence the level of knowledge of the APA to increase amongst stakeholders including to the extension officers. This would assist in providing effective and appropriate advisory services (which is based on legislation) to farmers, growers, producers, exporters and importers. Cameron et al. 2016 found that effective communication to small-holder farmers is critical and concluded that advice to the farmers must also be based on knowledge of legislation and latest information. Serem (2009) alluded that the majority of farmers lacks knowledge and experience challenges relating to international trade.

\subsubsection{Linkages of NPPOZA on plant health system to research institutions}

The findings on the relationship between linkages of the NPPOZA on plant health system to research institutions are presented, and it was found that the correlation was positive between these two variables, which was significant $((\mathrm{r})(60)=0.299 \mathrm{p}=0.020)$. A proper linkage of the NPPOZA with various research institutes is essential as the research component will assist in doing research for new pest as well as pest identification and confirmation.

Table 2 Spearman's correlation coefficients on plant health institutional arrangements $(n=60)$

\begin{tabular}{|l|l|l|l|}
\hline Variables & $\begin{array}{l}\text { Participation } \\
\text { in relevant } \\
\text { forums }\end{array}$ & $\begin{array}{l}\text { Budget } \\
\text { allocation/centralisation } \\
\text { for pest control }\end{array}$ & $\begin{array}{l}\text { Knowledge of } \\
\text { Agricultural Pests } \\
\text { Act }\end{array}$ \\
\hline $\begin{array}{l}\text { Linkages of NPPOZA with other } \\
\text { authority }\end{array}$ & $0.115^{\mathrm{NS}}$ & $0.055^{\mathrm{NS}}$ & $0.261^{*}$ \\
\hline
\end{tabular}




\begin{tabular}{|l|l|l|l|}
\hline Formal linkages & $0.333^{* *}$ & $0.070^{\mathrm{NS}}$ & $0.434^{* *}$ \\
\hline Availability of PH unit & $0.225^{\mathrm{NS}}$ & $0.120^{\mathrm{NS}}$ & $0.469^{* *}$ \\
\hline $\begin{array}{l}\text { Linkages of NPPOZA to } \\
\text { research institutions }\end{array}$ & $0.140^{\mathrm{NS}}$ & $0.299^{*}$ & $0.253^{\mathrm{NS}}$ \\
\hline
\end{tabular}

Correlations are highly significantly $(* *)$, significant $(*)$ at $\mathrm{p}<0.05$ or non-significant (NS)

\section{CONCLUSIONS AND RECOMMENDATIONS}

This paper concludes that formal linkages between the NPPOZA and PDAs do not exist in terms of the legislative and policy prescripts on plant health matters. The study further examined the relationship in relation to relevant pieces of legislation impacting on phytosanitary regulatory environment. This paper established that there are cross-cutting or overlapping issues among legislation such as the NEMBA and APA as well as PIA. This was found to appear on the import provision relating to plants, plant products and other regulated articles. For instance, the importation of biological control agents is covered in terms of the APA and the NEMBA. The study found that the relevant pieces of legislation do not provide for cross referencing clause. This study proved that plant health matters including regulatory aspects are administered at a national authority.

In this paper, recommendations informed by the findings of the study are provided for relevant Government Departments, policy makers, legislature, decision makers, financial delegate, DALRRD management, PDAs authority, DEFF: Biodiversity and Biosecurity unit regarding the plant health system. It is recommended that:

- The DALRRD and PDAs establish formal linkages based on policy and legislative framework on phytosanitary matters. It is recommended that national authorities and provincial structures should be formally linked to ensure that the plant health mandate is executed as well as proper allocation of the resources. In the interim, the linkages may be done through relevant agreements or memorandum of understanding whilst in the long term policy and legislative instruments should be developed to spell out the responsibilities and roles.

- The DALRRD establishes collaboration or cooperative models on plant health matters involving all relevant stakeholders, such as commodity groups, extension officers, Universities and research institutes. For example, through such collaboration, universities may be able to play a meaningful role in pest identification and publishing new research findings.

- The PDAs establishes plant health units at provincial level and the DALRRD should transfer some of the mandate to provincial authorities such as surveillance, awareness and promotion and possible plant health diagnostic services.

- The DALRRD allocates sufficient budget for plant pest control and management within its relevant branch structures at, which is outside the scope of the Disaster Management 
Funds. More funds should be allocated for operational activities for rapid response for pest outbreaks.

- The DALRRD and DEFF harmonise sections or provisions of the APA \& NEMBA which were found to have overlapping issues especially on the provisions for importation of plants, plant products and other regulated articles and to ensure that proper cross referencing is legislated to enhance service delivery and improve regulatory systems.

\section{REFERENCES}

AFRICAN UNION. 2013: INTER-AFRICAN PHYTOSANITARY COUNCIL (IAPSC). Final report. A country's structure and organization of a National Plant Protection Organization in Africa

ALBERTS, R., \& MOOLMAN, J. 2013. Protecting ecosystems by way of biological control: cursory reflections on the main regulatory instruments for biological control agents, present and future. PER: Potchefstroomse Elektroniese Regsblad, 16, 2

CAMERON, K. H., SOMACHANDRA, K. P., CURRY, C. N., JENNER, W. H., \& HOBBS, S. L. 2016. Delivering Actionable Plant Health Knowledge to Smallholder Farmers Through the Plantwise Program. Journal of Agricultural \& Food Information, 17, $212-$ 229

CENTRE FOR AGRICULTURE AND BIOSCIENCES INTERNATIONAL (CABI). 2017. Fall Armyworm: Impacts and Implications for Africa. Evidence Note (Summary Version), September 2017

CHINAPPEN, M. 2011. A Proposal for Phytosanitary Capacity Building Strategy in Africa. Technical Report

DANIELSEN, S., \& MATSIKO, F. B. 2014. Using a plant health system framework to assess plant clinic performance in Uganda. Food Security, 8, 345-359

DEPARTMENT OF AGRICULTURE (DOA). 2002. The Integrated Food Security Strategy for South Africa. Republic of South Africa. Pretoria

DEPARTMENT OF AGRICULTURE, FORESTRY AND FISHERIES (DAFF). 2011. Strategic Plan for the department of Agriculture, Forestry and Fisheries 2011/12 to 2014/15). Situational analysis

DEPARTMENT OF AGRICULTURE, FORESTRY AND FISHERIES (DAFF). 2013. The South African Emergency Plant Pest Response Plan (EPPRP) (2013). Plant Health Early Warnings. Pretoria

DEPARTMENT OF AGRICULTURE, FORESTRY AND FISHERIES (DAFF). 2015a. Agricultural Policy Action Plan, 2015 
DEPARTMENT OF AGRICULTURE, FORESTRY AND FISHERIES (DAFF). 2015b. Strategic Plan 201516 to 2019/20. Department of Agriculture, Forestry and Fisheries. National Policy Mandates. Pretoria

DEPARTMENT OF ENVIRONMENTAL AFFAIRS. 2015. Strategic Plan 2015/16-2019/20. Republic of South Africa. Pretoria

DEPARTMENT OF ENVIRONMENTAL AFFAIRS. 2018. National Environmental Management: Biodiversity Act 2004 (Act No. 10 of 2004). Draft Alien and Invasive Species Regulations

EBBELS, D. L. 2003. Principles of plant health and quarantine. CABI

FOOD AND AGRICULTURE ORGANISATION (FAO). 2007. International Standards for Phytosanitary Measures (ISPMs 5). Glossary of Phytosanitary Terms. International Plant Protection Convention (IPPC). Rome

FOOD AND AGRICULTURE ORGANISATION (FAO). 2011. International Plant Protection Convention

FLOOD, J. 2010. The importance of plant health to food security. Food Security, 2, 215-231

HANYANI-MLAMBO, B.T. 2002. Strengthening the pluralistic agricultural extension system: a Zimbabwean case study. Agricultural Research Council (ARC) Zimbabwe. Regional integration in Africa

INTERNATIONAL PLANT PROTECTION CONVENTION (IPPC). 1997. New Revised Text (NRT) of the International Plant Protection Convention (IPPC). Food and Agriculture Organisation of the United Nations, Rome, Italy

LUKAUSKAS, A., STERN, R.M., \& ZANINI, G. 2013. Handbook of Trade Policy for Development. Introduction. National Research Council (NRC). United States

MSISKA, K. K., BIGSBY, H., FRAMPTON. E \& WORNER, S. 2013. Establishing a more effective phytosanitary regulatory system: A Zambia case study. Journal of Biology, Agriculture and Healthcare, 3, 39-45

NATIONAL ENVIRONMENTAL MANAGEMENT: BIODIVERSITY ACT. 2004. Draft Alien and Invasive Species Regulations (2009). Department of Environmental Affairs and Tourism. Government Gazette. Notice 347 of 2009

NATIONAL ENVIRONMENTAL MANAGEMENT BIODIVERSITY ACT. 2016. National List of Terrestrial Invasive Invertebrate Species. Government Gazette

OERKE, E. C. 2006. Crop losses to pests. The Journal of Agricultural Science, 144, 31-43

OGDEN, S. C. 2012. Innovation in horticultural market access. In I International Conference on Postharvest Pest and Disease Management in Exporting Horticultural Crops, 973, 21-29 
REPUBLIC OF KENYA (RK). 2010. National Horticulture Policy. Ministry of Agriculture, Nairobi, Kenya

REPUBLIC OF SOUTH AFRICA (RSA). 1983. Agricultural Pests Act No.36 of 1983 (Act No.36 of 1983) as amended. Republic of South Africa. Pretoria

REPUBLIC OF SOUTH AFRICA (RSA). 1983. Agricultural Pests Act No.36 of 1983 (Act No.36 of 1983) as amended. Control Measures Amendment. R.1271 of 17 January 2017. Republic of South Africa. Pretoria

REPUBLIC OF SOUTH AFRICA (RSA). 1996. Constitution of the Republic of South Africa, 1996. Chapter 2: Bill of rights, Chapter 3: Cooperative government. Republic of South Africa

REPUBLIC OF SOUTH AFRICA (RSA). 2014. Plant Health (Phytosanitary) Policy of South Africa. Department of Agriculture, Forestry and Fisheries (DAFF). Pretoria: Government Gazette No.38102

REPUBLIC OF SOUTH AFRICA (RSA). 2005. Intergovernmental Relations Framework Act, 2005 (Act No.13 of 2005). Government Gazette No.27898. Cape Town

SCHRADER G, A. \& UNGER, J. 2003. Pant quarantine as a measure against invasive alien species: the framework of the International Plant Protection Convention and the plant health regulations in the European Union. Biological Invasions, 5, 357-364

SEREM, A. 2009. International trade opportunities and challenges for small scale horticultural production systems. In I All Africa Horticultural Congress 911, 53-60)

SHAUN, K. 2016. Food Protection and Security: Preventing and Mitigating Contamination during Food Processing and Production

SOUTHERN AFRICAN DEVELOPMENT COMMUNITY (SADC). 2001. Treaty of the Southern African Development Community, 17 August 1992; amended 14 August 2001 (hereinafter the SADC Treaty)

UNITED STATES DEPARTMENT OF AGRICULTURE (USDA). 2015. Plant Health System Analysis. Training Manuals. United States of America. Raleigh, North Carolina, Washington Metro

UNITED STATE DEPARTMENT OF AGRICULTURE (USDA). 2017. National Plant Health Emergency Management Framework. Animal and Plant Health Inspection Services. Plant Protection and Quarantine

VAPNEK, J., \& MANZELLA, D. 2006. Guidelines for the revision of national phytosanitary legislation. Food and Agriculture Organisation (FAO) 
S. Afr. J. Agric. Ext.

Vol. 49 No. 1, 2021: 13-29

http://dx.doi.org/10.17159/2413-3221/2021/v49n1a10774
Rambauli, Antwi, Mudau

(License: CC BY 4.0)

WORLD TRADE ORGANISATION (WTO). 2010. The WTO Series. Sanitary and Phytosanitary Measures. Switzerland

ZHOU Y., \& KUHLMANN, K. 2015. Seed Policy Harmonization in SADC and COMESA: The Case of Zimbabwe. Working Paper 